\title{
VEGF-A clinical significance in gastric cancers: Immunohistochemical analysis of a wide Italian cohort
}

\author{
E. Lastraioli ${ }^{\text {a,n }}$, L. Boni ${ }^{\text {b,n }}$, M.R. Romoli ${ }^{\text {a,m }}$, S. Crescioli ${ }^{\text {a }}$, \\ A. Taddei ${ }^{\mathrm{c}}$, S. Beghelli ${ }^{\mathrm{d}}$, A. Tomezzoli ${ }^{\mathrm{e}}$, C. Vindigni ${ }^{\mathrm{f}}$, \\ L. Saragoni ${ }^{g}$, L. Messerini ${ }^{a}$, M. Bernini ${ }^{\text {h}}$, L. Bencini ${ }^{\mathrm{h}}$, \\ E. Giommoni ${ }^{i}$, G. Freschi ${ }^{\text {c }}$, F. Di Costanzo ${ }^{i}$, A. Scarpa ${ }^{d}$, \\ P. Morgagni ${ }^{j}$, M. Farsi ${ }^{\text {h}}$, F. Roviello ${ }^{\text {k }}$, G. De Manzoni ${ }^{1}$, P. Bechi ${ }^{\text {c }}$, \\ A. Arcangeli ${ }^{a}, *$, \\ On behalf of Gruppo Italiano di Ricerca Cancro Gastrico (GIRCG) \\ ${ }^{a}$ Department of Clinical and Experimental Medicine, University of Florence, Largo GA Brambilla 3, \\ 50134 Florence, Italy \\ ${ }^{\mathrm{b}}$ Clinical Trials Coordinating Center, Azienda Ospedaliero-Universitaria Careggi/Istituto Toscano Tumori, \\ Largo GA Brambilla 3, 50134 Florence, Italy \\ ' Surgery and Translational Medicine, University of Florence, Largo GA Brambilla 3, 50134 Florence, Italy \\ ${ }^{\mathrm{d}}$ Department of Pathology and Diagnostics, University of Verona, Piazzale LA Scuro 10, 37134 Verona, Italy \\ e Pathology Division, Borgo Trento Hospital, Piazzale A Stefani 1, 37134 Verona, Italy \\ ${ }^{\mathrm{f}}$ Pathology Division, Azienda Ospedaliero-Universitaria Senese, Viale M Bracci 16, 53100 Siena, Italy \\ ${ }^{\mathrm{g}}$ Pathology Division, Morgagni-Pierantoni Hospital, Via C Forlanini 34, 47121 Forlì, Italy \\ ${ }^{\mathrm{h}}$ General Surgery and Surgical Oncology, Azienda Ospedaliero-Universitaria Careggi, Largo GA Brambilla 3 , \\ 50134 Florence, Florence, Italy \\ ${ }^{\mathrm{i}}$ Medical Oncology, Azienda Ospedaliero-Universitaria Careggi, Largo GA Brambilla 3, 50134 Florence, \\ Florence, Italy \\ ${ }^{\mathrm{j}}$ General Surgery, Morgagni-Pierantoni Hospital, Via C Forlanini 34, 47121 Forlì, Italy \\ ${ }^{\mathrm{k}}$ Department of General Surgery and Oncology, University of Siena, Viale M Bracci 16, 53100 Siena, Italy \\ ${ }^{1}$ Division of Surgery, University of Verona, Piazzale LA Scuro 10, 37134 Verona, Italy
}

Accepted 31 March 2014

Available online 12 April 2014

\begin{abstract}
Purpose: The clinical significance of VEGF-A expression in gastric cancer (GC) has been reported with contradicting results. We analyzed the expression and clinical significance of VEGF-A in a wide Italian cohort of GC specimens.

Methods: VEGF-A expression was tested by immunohistochemistry in 507 patients with GC of all clinical stages. The impact of VEGF-A on overall survival (OS) was evaluated in conjunction with clinical and pathological parameters.

Results: In the Italian cohort we studied VEGF-A was not an independent prognostic factor neither at the univariate nor at multivariate analysis.

Conclusions: Although frequently expressed, in our study VEGF-A was not able to discriminate between groups of patients with different risk. (c) 2014 Elsevier Ltd. All rights reserved.
\end{abstract}

Keywords: VEGF-A; Gastric cancer; Immunohistochemistry; Prognostic markers

\footnotetext{
* Corresponding author. Department of Clinical and Experimental Medicine, Internal Medicine Section, Viale GB Morgagni, 50, 50134 Florence, Italy. Tel.: +39055 2751283; fax: +390552751281.

E-mail address: annarosa.arcangeli@unifi.it (A. Arcangeli).

${ }^{m}$ Present address: Surgery and Translational Medicine, University of Florence, Largo GA Brambilla 3, 50134 Florence, Italy.

${ }^{\mathrm{n}}$ Equally contributed to this work.
} 


\section{Introduction}

GC is the fourth most common cancer and the second leading cause of cancer-related death worldwide. ${ }^{1}$ The vast majority of GC are adenocarcinomas; they are diagnosed after they have invaded the muscularis propria and are therefore classified as Advanced Gastric Cancers (AGC). The detection of a GC which is still confined to the mucosa and submucosa (Early Gastric Cancer, EGC) leads to a better prognosis. ${ }^{2}$ It has been demonstrated that GC incidence and mortality show geographic variability and Europe has an intermediate incidence rate, between high incidence countries (such as Japan) and low incidence countries (African countries). ${ }^{3}$ Despite earlier diagnosis, radical surgery and the development of novel adjuvant therapies, including target therapies, have improved prognosis for GC, the 5-years survival rate, across all the TNM stages, is only about $28 \%$, based on data provided by the American Cancer Society. Moreover, Japanese survival rates are higher than those observed in Western countries and within Europe, consistent differences can be observed. ${ }^{4}$ Standard chemotherapy, both in resectable and advanced disease, has however limited efficacy. Hence, the identification of novel molecular markers, as well as new cancerogenetic mechanisms and targets for therapeutic interventions, are urgently needed to improve prognosis.

A relevant aspect of tumor growth is represented by intratumoral angiogenesis. It has been hypothesized that cancer cells begin to promote angiogenesis early in tumorigenesis. This early "angiogenic switch" is characterized by oncogene-driven tumor expression of pro-angiogenic proteins. ${ }^{6}$ Among them, the Vascular Endothelial Growth Factor-A (VEGF-A) is one of the most relevant angiogenic factors, ${ }^{7}$ whose expression is regulated by both oxygen tension $^{8}$ and polypeptide growth factors, cytokines, as well as oncogenic mutations of relevant intracellular signaling components (reviewed in Ref. 9). VEGF-A and its receptors have been identified to critically influence tumor-related angiogenesis, in several cancer types, including GC. ${ }^{10}$ VEGF-A impact on prognosis has been demonstrated by meta-analysis in different cancers such as hepatocellular ${ }^{11}$ and pancreatic cancer. ${ }^{12}$ Despite numerous studies, however, the prognostic significance of VEGF expression in GC is still under debate ${ }^{13-21}$ and an extensive meta-analysis has been recently published ${ }^{22}$ showing that ethnicity is a predictive factor of the effect of VEGF-A on prognosis.

Very few papers evaluating VEGF-A clinical significance in big cohorts of non-Asian individuals have been published so far. The majority of the studies analyzed Asian patients whose pathological characteristics are quite different from those of Western countries' subjects. Indeed, from a comparison between a Japanese and a British cohort ${ }^{23}$ it emerged a prevalence of Lauren's intestinal type in European patients, and of diffuse type in Japanese subjects. Moreover, the Japanese cohort showed high percentages of TNM stage I and II with respect to stages III and IV, while in the British cohort the distribution was more homogeneous.

The present paper was aimed at better defining the expression profile and prognostic role of VEGF-A in a wide Italian cohort of GC samples, encompassing all pathological stages.

\section{Materials and methods}

\section{Patients and tissue specimens}

Tissue samples $(n=190)$ were prospectively obtained after informed written consent from patients who underwent surgery with curative or palliative intent for primary gastric cancers at the Department of Surgery and Translational Medicine, University of Florence and the General Surgery and Surgical Oncology, Azienda Ospedaliero-Universitaria, Careggi, Florence, Italy. Patients affected by viral hepatitis or who had undergone pre-operative radiotherapy or chemotherapy were excluded from the study. Samples were taken in the operating room and a sample of paired normal gastric mucosa was collected from the operative specimens at least $10 \mathrm{~cm}$ from the tumor, and from the same region of the stomach containing the tumor, when applicable.

Moreover, a multicenter cohort of GC archival samples ( $n=389)$ mainly assembled as Tissue Micro Arrays was collected by Department of Pathology and Diagnostics (University of Verona), Department of Pathological Anatomy (AOUS, Siena), Department of General Surgery and Oncology (University of Siena), Pathology Division, Borgo Trento Hospital (Verona), General Surgery and Division of Pathology, Morgagni-Pierantoni Hospital (Forlì).

Diagnosis and histological grading were assessed in all cases using standard criteria by experienced pathologists (LM, AT, CV, and LS). The study population was represented by 508 patients with complete follow up information.

\section{Immunohistochemistry (IHC)}

Due to the broad expression of VEGF-A in stromal cells of the gastric submucosa ${ }^{24}$ that might raise false positive results with standard molecular techniques, VEGF-A expression was retrospectively tested by IHC, and performed as previously reported ${ }^{25}$ using anti-VEGF-A antibody (Polyclonal antibody anti VEGF-A (A-20), Santa Cruz Biotechnology; Santa Cruz CA, USA, 1: 100 dilution). As a preliminary step, we validated the antibody performing Western Blot assays and immunocytochemistry (see below) and optimized the IHC procedure ${ }^{25}$ in different primary tissues (high grade astrocytomas, renal tissue and normal colorectal tissue), that served as positive internal controls for VEGF-A staining. The staining background due to the expression of VEGF-A in stromal and inflammatory cells was considered as non-specific staining. Nevertheless, while evaluating the immunohistochemistry results only 
positive tumor cells were considered. Negative controls (no primary antibody) were included in each IHC experiment. After dewaxing and dehydrating the sections, endogenous peroxidases were blocked with a $1 \% \mathrm{H}_{2} \mathrm{O}_{2}$ solution in PBS. Subsequently, antigen retrieval was performed with Proteinase K $(5 \mu \mathrm{g} / \mathrm{ml})$ Because of the intracellular localization of the antigens, tissue permeabilization was required, therefore treatment with blocking solution and permeabilization were carried out (Ultra V Block containing 0.1\% Triton X100, LabVision; Fremont CA, USA). Antibodies were incubated overnight at $4{ }^{\circ} \mathrm{C}$. Immunostaining was performed with a commercially available kit (PicTure Max kit, Invitrogen; Carlsbad CA, USA) according to manufacturer's instructions. Stained sections were analyzed at a total magnification of $40 \times$ field by field, from top left to bottom right. A significant VEGF-A labeling was detected in GC samples where the protein was mainly expressed in the cytoplasm of cancerous epithelial cells, with a low expression in the tumor stroma. To evaluate the VEGF-A status of the samples, only epithelial-derived tumor cells were taken into account, while the signal detected in stromal or inflammatory cells was not considered. VEGF-A was scored as the number of positive tumor cells over total tumor cells, first setting the threshold value, using different cut offs. Percentage scores were then categorized using the $0 \%$ cutoff ( $0 \%$ staining vs any staining), the $10 \%$ cutoff ( $<10 \%$ tumor cell staining vs $\geq 10 \%$ ), the $25 \%$ ( $<25 \%$ tumor cell staining vs $\geq 25 \%)$ and the $50 \%(<50 \%$ tumor cell staining vs $\geq 50 \%$ ). Since the vast majority of the samples belonged to the highest score categories, no substantial difference emerged in the three cut off values groups $(10 \%$, $25 \%, 50 \%)$. In particular, the percentages of low score samples were $12.3 \%, 14.2 \%$ and $16.1 \%$ (with $<10 \%,<25 \%$ and $<50 \%$ cut-offs, respectively) while high score samples were $87.7 \%, 85.8 \%$ and $83.9 \%$ (with $>10 \%,>25 \%$ and $>50 \%$ cut offs, respectively). We argued that no significant biological differences characterized the different scoring groups. Hence, assignment of a positive score was performed when the sample showed more than $10 \%$ positive cells according to Galizia et al., $2004^{26}$ and as previously reported by other groups and by us. ${ }^{17,25}$ Results were evaluated by two independent investigators (EL and MRR). A third joint observation with conclusive agreement as well as the independent review of the slides by a third observer (SB) was performed. When needed, an additional review by experienced pathologists of each participating center was performed. Interobserver agreement was evaluated according to the simple Cohen's $k$ of concordance and its $95 \%$ confidence interval.

\section{Western Blot (WB)}

Diluted serum samples were heated in reducing Laemmli buffer $(6.25 \mathrm{mM}$ Tris- $\mathrm{HCl} \mathrm{pH} 6.8,1 \%$ glycerol, $2 \%$ SDS, $2 \% \beta$-mercaptoethanol and $0.0012 \%$ bromophenol blue) at $95{ }^{\circ} \mathrm{C}$ for $5 \mathrm{~min}$, separated by $10 \%$ SDS-
PAGE and transferred to a PVDF membrane (Amersham). After transfer, the membrane was blocked for $2 \mathrm{~h}$ at room temperature with PBS + Tween-20 0.1\% (T-PBS), containing 5\% BSA (T-PBS-BSA) and incubated overnight at $4{ }^{\circ} \mathrm{C}$ with anti-VEGF-A antibody (A-20, Santa Cruz Biotechnology), diluted 1:500 in T-PBS-BSA. The membrane was then washed 3 times with T-PBS and incubated with anti-rabbit peroxidase-conjugated secondary antibody (Sigma) diluted 1:10,000 in T-PBS-BSA for $45 \mathrm{~min}$ at room temperature. After 3 washes with T-PBS, the membrane was revealed by a chemiluminescent reaction with ECL (Amersham).

Table 1

Characteristics of patients excluded and included into the statistical analyses and distributions of clinical and pathological variables after multiple imputation of missing values.

\begin{tabular}{|c|c|c|c|}
\hline \multirow[t]{2}{*}{ Variable } & $\begin{array}{l}\text { Patients } \\
\text { excluded from } \\
\text { the analyses } \\
(N=71)\end{array}$ & $\begin{array}{l}\text { Patients } \\
\text { included } \\
\text { into the } \\
\text { analyses } \\
(N=508)\end{array}$ & $\begin{array}{l}\text { Study } \\
\text { cohort } \\
\text { after } \\
\text { multiple } \\
\text { imputation } \\
(N=508)\end{array}$ \\
\hline & No. (\%) & No. $(\%)$ & $\%$ \\
\hline \multicolumn{4}{|l|}{ Age, years } \\
\hline Median (range) & $71(31-86)$ & $67.5(30-90)$ & $68(30-90)$ \\
\hline$<70$ & $31(43.7)$ & $290(57.1)$ & 57.3 \\
\hline$\geq 70$ & 39 (54.9) & $216(42.5)$ & 42.7 \\
\hline Missing value & $1(1.4)$ & $2(0.4)$ & - \\
\hline \multicolumn{4}{|l|}{ Gender } \\
\hline Male & $44(62.0)$ & $324(63.8)$ & 63.8 \\
\hline Female & $27(38.0)$ & $184(36.2)$ & 36.2 \\
\hline \multicolumn{4}{|c|}{ Site of primary tumor } \\
\hline $\begin{array}{l}\text { Antrum, } \\
\text { cardias }\end{array}$ & $49(69.0)$ & $231(45.5)$ & 45.7 \\
\hline Body & $14(19.7)$ & $131(25.8)$ & 25.9 \\
\hline Fundus & $4(5.6)$ & $113(22.2)$ & 22.3 \\
\hline $\begin{array}{l}\text { Gastric stump, } \\
\text { linitis plastica }\end{array}$ & $2(2.8)$ & $31(6.1)$ & 6.1 \\
\hline Missing value & $2(2.8)$ & $2(0.4)$ & - \\
\hline \multicolumn{4}{|l|}{ TNM stage } \\
\hline I & $28(39.4)$ & $69(13.6)$ & 13.6 \\
\hline II & $10(14.1)$ & $89(17.5)$ & 17.5 \\
\hline III & $19(26.8)$ & $190(37.4)$ & 37.5 \\
\hline IV & 12 (16.9) & $159(31.3)$ & 31.3 \\
\hline Missing value & $2(2.8)$ & $1(0.2)$ & - \\
\hline \multicolumn{4}{|c|}{ Pathological grading } \\
\hline G1 & $7(9.9)$ & $24(4.7)$ & 4.9 \\
\hline G2 & $27(38.0)$ & $154(30.3)$ & 31.5 \\
\hline G3 & $27(38.0)$ & $292(57.5)$ & 61.5 \\
\hline G4 & $0(-)$ & $9(1.8)$ & 2.1 \\
\hline Missing value & $10(14.1)$ & $29(5.7)$ & - \\
\hline \multicolumn{4}{|l|}{ Lauren type } \\
\hline Intestinal & $41(57.7)$ & $317(62.4)$ & 63.8 \\
\hline Diffuse & $20(28.2)$ & $128(25.2)$ & 25.5 \\
\hline Mixed & $5(7.0)$ & $53(10.4)$ & 10.7 \\
\hline Missing value & $5(7.0)$ & $10(2.0)$ & - \\
\hline \multicolumn{4}{|l|}{ VEGF-A status } \\
\hline Negative & $8(11.3)$ & $42(8.3)$ & 12.3 \\
\hline Positive & $36(50.7)$ & $410(80.7)$ & 87.7 \\
\hline Missing value & $27(38.0)$ & $56(11.0)$ & - \\
\hline
\end{tabular}


A

WB: anti- VEGF-A antibody
B

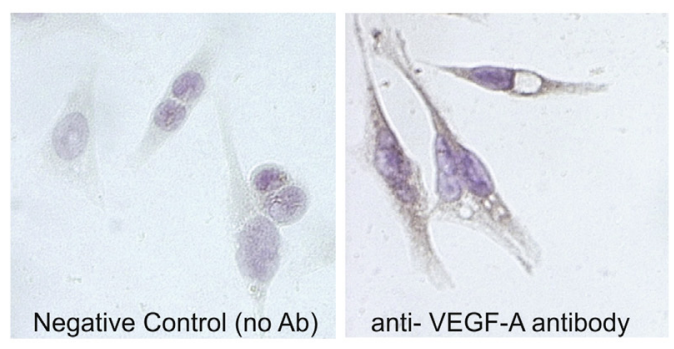

Figure 1. Anti-VEGF-A antibody specificity testing. A) WB experiments were performed on serum samples displaying high levels of VEGF-A (previously determined by ELISA assay, mean value: $1399.14 \pm 251.88 \mathrm{pg} / \mathrm{ml}$ vs $661.81 \pm 121.44 \mathrm{pg} / \mathrm{ml}$ in healthy donor serum samples). A band corresponding to about $24 \mathrm{kDa}$ is evident (see arrow) showing the ability of the antibody to selectively bind VEGF-A monomer in reduced serum samples. B) ICC on HCT116 cells secreting high levels of VEGF-A $\left(7.3 \pm 2.5 \mathrm{ng} / 10^{6}\right.$ cells vs $2.2 \pm 0.17$ in HEK293 cells $\left.{ }^{29}\right)$. A positive reaction is evident in the cytoplasm of tumor cells, while is not detectable in the Control sample (with no primary antibody, panel on the left).

\section{Immunocytochemistry (ICC)}

ICC was performed on HCT116 cell line. Cells were cultured in RPMI 1640 (Euroclone) supplemented with $10 \%$ Fetal Calf Serum (Euroclone) and $2 \mathrm{mM} \mathrm{L-Glutamine.}$ Cells were grown on glass coverslips, washed twice in PBS and fixed in $90 \%$ ethanol for 10 min at room temperature with gentle agitation. Coverslips were then air-dried and stored at room temperature. For ICC experiments, coverslips were treated with $0.1 \% \mathrm{H}_{2} \mathrm{O}_{2}$ for 15 min at room temperature, to ensure endogenous peroxidases blocking and then incubated with Ultra Vision Protein Block solution (Fisher Scientific) with $0.1 \%$ Triton X-100 for $20 \mathrm{~min}$ at room temperature. Cells were then incubated with antiVEGF-A antibody (A-20, Santa Cruz Biotechnology) diluted 1:100 in PBS-Ultra Vision Protein Block (10:1, v/ $\mathrm{v})$ for $2 \mathrm{~h}$ at room temperature. Immunostaining was carried out with PicTure Max kit and DAB (Invitrogen). For negative control samples, no primary antibody was added to the PBS-Ultra Vision Protein Block solution. Coverslips were then counterstained with Mayer Hematoxylin and mounted on glass slides.

\section{Statistical analysis}

The distributions of all studied patients were reported with respect to their demographic, clinical, and biologic characteristics and were summarized as frequencies and percentage. Continuous variables were reported as median and range of variation. To avoid the exclusion of cases with missing data, the multiple imputation method was used (10 imputations). Logistic regression and regression methods were used for imputation of categorical and continuous variables, respectively. Missing-at-random assumptions were made. The following demographic, clinical and biological variables were investigated: age at the intervention, gender, site of primary, TNM stage, pathological grading, Lauren type and VEGF-A status. Both in the association and survival analyses, age was categorized in two groups ( $<70$ years vs $\geq 70$ years). As a measure of the strength of the association between the VEGF-A expression and each other characteristics, the odds ratio (OR) value and its 95\% confidence interval (CI) was estimated with a univariate logistic regression model, combining the results of the analyses of imputations. The statistical significance of odds ratios was evaluated according to the likelihood ratio test. All the variables were investigated for their impact on overall survival (OS). OS was defined as the time between intervention and death,

Table 2

Association between VEGF-A expression and clinical and pathological variables.

\begin{tabular}{|c|c|c|c|}
\hline Variable & $\begin{array}{l}\text { VEGF-A } \\
\text { positivity rate }\end{array}$ & OR $(95 \% \mathrm{CI})$ & $P$ value \\
\hline \multicolumn{4}{|l|}{ Age, years } \\
\hline$<70$ & $88.1 \%$ & 1 (ref.) & \multirow[t]{2}{*}{0.564} \\
\hline$\geq 70$ & $87.2 \%$ & $0.90(0.44-1.85)$ & \\
\hline \multicolumn{4}{|l|}{ Gender } \\
\hline Male & $88.2 \%$ & 1 (ref.) & \multirow[t]{2}{*}{0.699} \\
\hline Female & $86.9 \%$ & $0.88(0.43-1.81)$ & \\
\hline \multicolumn{4}{|c|}{ Site of primary tumor } \\
\hline Antrum, cardias & $88.0 \%$ & 1 (ref.) & \multirow[t]{4}{*}{0.809} \\
\hline Body & $89.0 \%$ & $1.09(0.49-2.43)$ & \\
\hline Fundus & $86.6 \%$ & $0.88(0.42-1.87)$ & \\
\hline $\begin{array}{l}\text { Gastric stump, } \\
\text { linitis plastica }\end{array}$ & $83.9 \%$ & $0.70(0.23-2.14)$ & \\
\hline \multicolumn{4}{|l|}{ TNM stage } \\
\hline I & $82.5 \%$ & 1 (ref.) & \multirow[t]{4}{*}{0.397} \\
\hline II & $93.3 \%$ & $2.67(0.54-13.2)$ & \\
\hline III & $88.2 \%$ & $1.44(0.34-6.14)$ & \\
\hline IV & $86.4 \%$ & $1.23(0.27-5.68)$ & \\
\hline \multicolumn{4}{|l|}{ Pathological grading } \\
\hline $\mathrm{G} 1, \mathrm{G} 2$ & $91.3 \%$ & 1 (ref.) & \multirow[t]{2}{*}{0.106} \\
\hline G3, G4 & $85.7 \%$ & $0.55(0.25-1.21)$ & \\
\hline \multicolumn{4}{|l|}{ Lauren type } \\
\hline Intestinal & $90.6 \%$ & 1 (ref.) & \multirow[t]{3}{*}{0.212} \\
\hline Diffuse & $85.2 \%$ & $0.58(0.25-1.31)$ & \\
\hline Mixed & $76.7 \%$ & $0.33(0.10-1.09)$ & \\
\hline
\end{tabular}

Abbreviations: ref., reference group. 
Table 3

Univariate and multivariate evaluation of prognostic role for overall survival of clinical and pathological variables.

\begin{tabular}{|c|c|c|c|c|}
\hline \multirow[t]{2}{*}{ Variable } & \multicolumn{2}{|l|}{ Univariate analysis } & \multicolumn{2}{|c|}{ Multivariate analysis } \\
\hline & HR $(95 \% \mathrm{CI})$ & $P$ value & $\operatorname{HR}(95 \% \mathrm{CI})$ & $P$ value \\
\hline \multicolumn{5}{|l|}{ Age, years } \\
\hline$<70$ & 1 (ref.) & \multirow[t]{2}{*}{$<0.001$} & 1 (ref.) & \multirow[t]{2}{*}{$<0.001$} \\
\hline$\geq 70$ & $1.63(1.34-1.99)$ & & $2.29(1.86-2.82)$ & \\
\hline \multicolumn{5}{|l|}{ Gender } \\
\hline Male & 1 (ref.) & 0.012 & 1 (ref.) & 0.006 \\
\hline \multicolumn{5}{|l|}{ Site of primary tumor } \\
\hline Antrum, cardias & 1 (ref.) & \multirow[t]{4}{*}{$<0.001$} & 1 (ref.) & \multirow[t]{4}{*}{0.023} \\
\hline Body & $1.14(0.89-1.47)$ & & $1.05(0.81-1.34)$ & \\
\hline Fundus & $1.37(1.06-1.76)$ & & $1.20(0.92-1.57)$ & \\
\hline Gastric stump, linitis plastica & $2.52(1.67-3.80)$ & & $1.98(1.30-3.04)$ & \\
\hline \multicolumn{5}{|l|}{ TNM stage } \\
\hline I & 1 (ref.) & \multirow[t]{3}{*}{$<0.001$} & 1 (ref.) & \multirow[t]{3}{*}{$<0.001$} \\
\hline II & $2.17(1.40-3.38)$ & & $2.36(1.50-3.71)$ & \\
\hline IV & $7.09(4.68-10.7)$ & & $8.40(5.39-13.1)$ & \\
\hline \multicolumn{5}{|l|}{ Pathological grading } \\
\hline $\mathrm{G} 1, \mathrm{G} 2$ & 1 (ref.) & \multirow[t]{2}{*}{0.207} & 1 (ref.) & \multirow[t]{2}{*}{0.045} \\
\hline $\mathrm{G} 3, \mathrm{G} 4$ & $1.14(0.93-1.41)$ & & $0.76(0.58-0.99)$ & \\
\hline \multicolumn{5}{|l|}{ Lauren type } \\
\hline Intestinal & 1 (ref.) & \multirow[t]{3}{*}{$<0.001$} & 1 (ref.) & \multirow[t]{3}{*}{0.017} \\
\hline Diffuse & $1.55(1.23-1.94)$ & & $1.36(1.02-1.81)$ & \\
\hline Mixed & $1.79(1.30-2.45)$ & & $1.64(1.14-2.35)$ & \\
\hline \multicolumn{5}{|l|}{ VEGF-A status } \\
\hline Negative & 1 (ref.) & \multirow[t]{2}{*}{0.510} & 1 (ref.) & \multirow[t]{2}{*}{0.801} \\
\hline Positive & $1.00(0.59-1.68)$ & & $0.99(0.70-1.40)$ & \\
\hline
\end{tabular}

Abbreviations: ref., reference group.

whatever the cause. Observation time of patients alive at the last follow-up visit was censored. Median follow-up time was estimated according to the Kaplan-Meier inverse method. ${ }^{27}$ Univariate and multivariate hazard ratios (HRs) estimates, and appropriate 95\% CIs, were calculated by means of the Cox proportional hazard model, combining the results of the analyses of imputations. The statistical significance of HRs was evaluated according to the likelihood ratio test. The multivariate Cox regression model was fitted including in the model all the investigated parameters. The presence of interaction on OS between the VEGF-A status and other characteristics was verified with the interaction test. A two-sided $P \leq 0.05$ was considered significant in all analyses. No adjustment for multiple comparisons was made. Statistical analyses were performed by LB using SAS version 9.2 (SAS Institute, Cary, NC).

\section{Results}

\section{Characteristics of study cohort}

Patients were enrolled from different Italian centers (Florence, Verona, Siena and Forlì). As shown in Table 1 the group of 71 patients excluded from analysis did not significantly differ from the study population. Patient samples encompassed all TNM stages, with higher percentages in stages III and IV. As it can be observed from Table 1, a slight prevalence of males and G3 pathological grade characterized the cohort under study. Moreover, $63.8 \%$ of the samples were classified as Lauren's intestinal type, according to the most frequent histotype in Italy. ${ }^{28}$

To confirm the specificity of anti-VEGF-A antibody, preliminary experiments were performed. In particular, Western Blot assay was performed on human serum samples with high VEGF-A levels (previously determined by Human VEGF Quantikine ELISA kit). As shown in Fig. 1A, WB results indicate that anti-VEGF-A antibody specifically binds VEGF-A monomer in reduced serum samples, in which a band of about $24 \mathrm{kDa}$ is evident, according to the product's datasheet.

To further confirm the antibody specificity, ICC experiments were carried out on HCT116 cell line, already characterized for VEGF-A secretion. ${ }^{29}$ In Fig. 1B, representative pictures of ICC experiments are reported, showing VEGF-A expression in the cytoplasm of neoplastic cells (right panel), while no immunostaining can be observed in the negative control sample (left panel).

The expression of VEGF-A in primary GC was studied only by IHC, due to the broad expression of VEGF-A in stromal cells of the gastric submucosa. ${ }^{24}$ Normal gastric mucosa did not express the protein (Fig. 2, panels A and B), while a low expression was observed in the stroma (more evident in panel B), as expected. When analyzing tumor samples a significant VEGF-A labeling was detected in GC samples of Lauren's intestinal type (Fig. 2, panels $\mathrm{C}$ and $\mathrm{D}$ ) where the protein was mainly expressed 

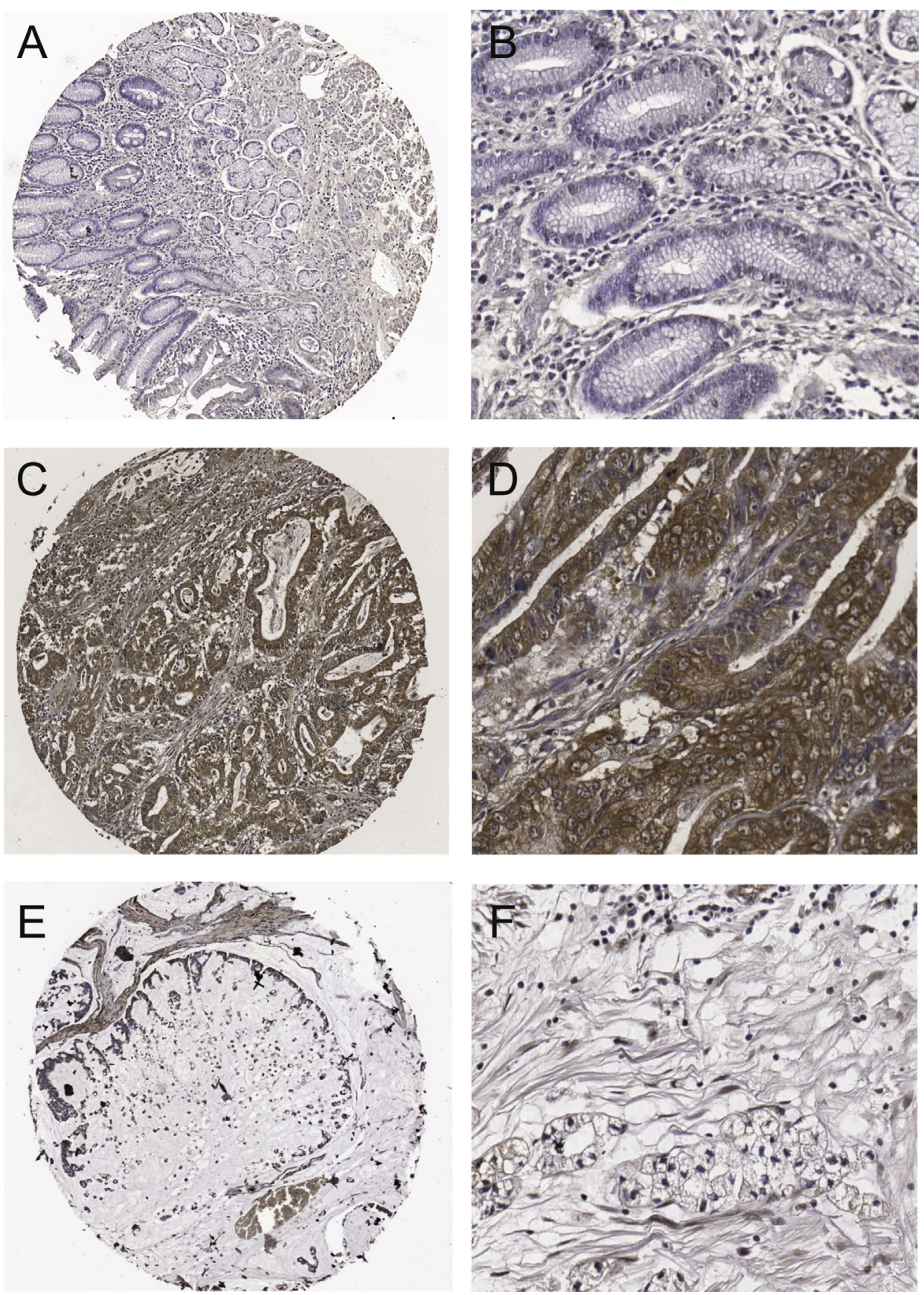

Figure 2. Immunohistochemical staining for VEGF-A in GC specimens. IHC experiments and assessment of score were performed as described in Materials and methods. A) IHC of a representative specimen of normal gastric mucosa. The lining epithelium does not express the protein in contrast to the stroma. B) Higher magnification of the same sample as in A). C) IHC of a Lauren's intestinal type adenocarcinoma sample strongly positive for VEGF-A expression. VEGF-A staining was intense and diffuse in the cytoplasm of tumor cells, with a weaker positivity in the stroma. D) Higher power microphotograph of the sample reported in C. E) IHC of a diffuse type adenocarcinoma, showing no VEGF-A expression. F) Higher magnification picture of the sample in E). Images were acquired with Aperio Image Scope v.11.0.2.725. Magnification: A, C, E: 6×; B, D, F: 20×.

in the cytoplasm of cancerous epithelial cells, while nuclei were negative, as expected. A lower expression of the protein was observed in the tumor stroma (Fig. 2D). Samples of the diffuse type turned out to be negative (Fig. 2, panels E and F). A positive score for VEGF-A was assigned when the sample showed more than $10 \%$ positive cells. ${ }^{26}$
On the whole, $87.7 \%$ of the samples expressed VEGF-A with a high immunoreactivity score. No associations between clinical-pathological parameters and VEGF-A expression emerged (Table 2).

The samples were evaluated by two independent investigators and the $k$ value related to the interobserver measure of agreement was 0.92 (95\% CI: 0.85-0.99). 


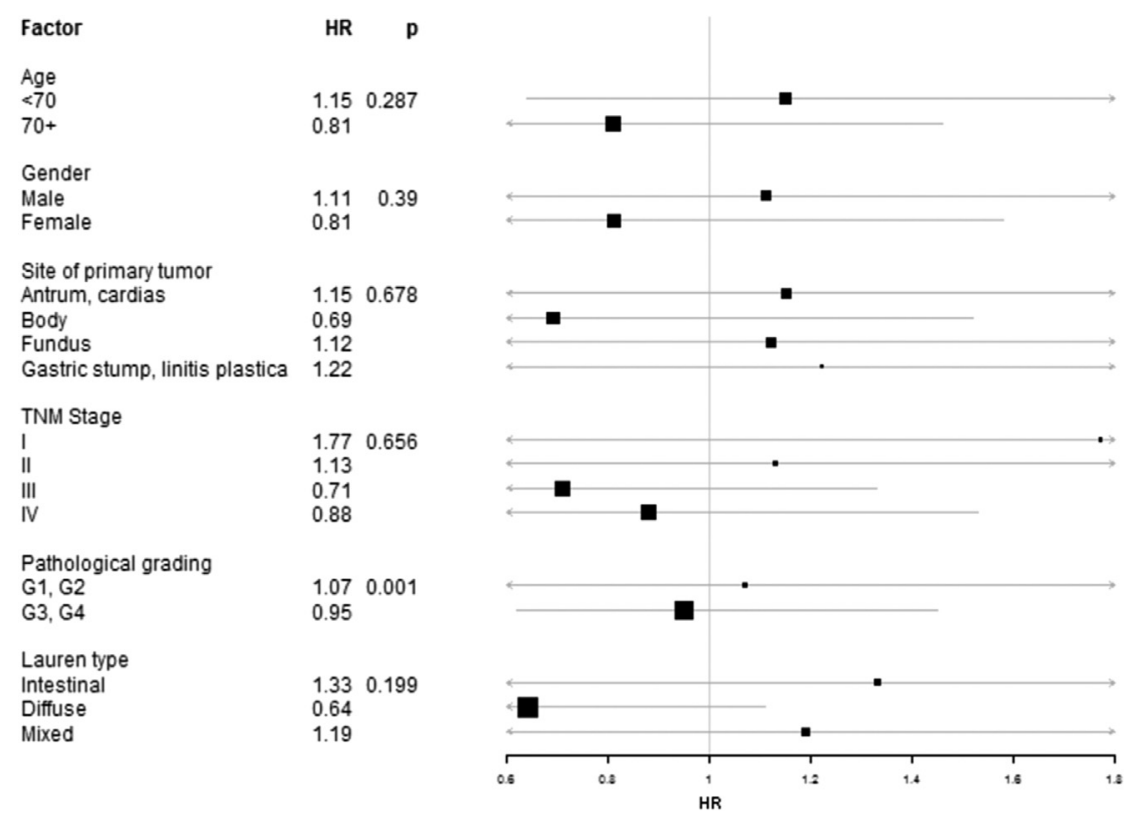

Figure 3. Interaction analyses on OS between VEGF-A and other clinical and pathological parameters. Values of HR $<1$ indicate a protective role of VEGF-A.

\section{Prognostic markers evaluation}

After a median follow-up of 11.1 years (IQR: 7.3-15.0) 391 deaths were observed.

At the univariate analyses, age $\geq 70$ years, male sex, site (gastric stump and linitis plastica), advanced stages and diffuse/mixed Lauren were associated with a worse prognosis (Table 3). On the contrary, VEGF-A did not show any impact on overall survival (OS) $(\mathrm{HR}=1.00,95 \%$ CI: $0.59-1.68 ; P=0.510)$. From the comparison of early-onset GC ( $\leq 45$ years) with late-onset GC ( $>45$ years) no statistically significant results emerged, due to the quite low percentage of patients belonging to the early-onset group (only 5\%).

The multivariate analysis confirmed the results obtained at the univariate analysis (Table 3).

Finally, one statistically significant interaction on OS was observed between pathological grading and VEGF expression $(P=0.001)$ although not clinically relevant, with an $\mathrm{HR}=1.07$ in $\mathrm{G} 1-\mathrm{G} 2$ samples and a $\mathrm{HR}=0.95$ in $\mathrm{G} 3-\mathrm{G} 4$ samples (Fig. 3).

\section{Discussion}

In the present paper we evaluated VEGF-A expression and clinical significance in a huge cohort of non-Asian individuals suffering from GC. In particular, VEGF-A expression was analyzed in a large series of GC patients all belonging to Italian ethnicity, using methodologies and antibodies employed in different Research and Medical Centers. ${ }^{17,25}$ Study population was characterized by a slight prevalence of males, G3 pathological grading and TNM stages III and IV. As expected, ${ }^{28}$ the intestinal Lauren's histological type prevailed. In our series, VEGF-A expression was not associated with clinico-pathological characteristics and had no impact on overall survival. A statistically significant interaction on OS was observed between pathological grading and VEGF expression, although not clinically relevant. It should be also noted that in our series VEGF-A is expressed by the majority of samples $(87.7 \%)$ and this imbalance makes it quite difficult to draw precise correlations.

To our knowledge a very few papers evaluating the prognostic value of VEGF-A in big cohorts of non-Asian individuals have been published so far. In fact, the majority of the studies analyzed Asian patients, whose pathological characteristics are quite different from those of Western countries' subjects. In this case, data concerning VEGF-A prognostic impact mainly address it as a negative factor. $^{13,14,16,19,21}$ Only a paper, reporting data obtained in a big cohort of patients, found no association between VEGF-A expression and prognosis in GC evaluated by IHC using paraffin-embedded samples, ${ }^{18}$ in agreement with our findings. Moreover, a meta-analysis whose results have been published in $2012,{ }^{22}$ showed that VEGF-A expression is associated with poor prognosis in Asian population, while this correlation is lacking in non-Asian cohorts.

Similarly to the present, the study conducted by Lieto et al. ${ }^{17}$ investigated the prognostic impact of VEGF-A expression in patients of Italian origin, although reaching a different conclusion. This discrepancy could be traced back to the fact that Lieto et al. analyzed a smaller number $(88$ vs 508) of patients, with different clinico-pathological characteristics, such as a higher percentage of diffuse type cases.

From this scenario, and our data support this hypothesis, it emerges that VEGF-A expression has a negative 
prognostic impact only in Asian GC patients, ${ }^{16,17,30-33}$ with low or null impact in Western country populations.

\section{Acknowledgments}

This work was supported by Associazione Italiana per la Ricerca sul Cancro (AIRC, Grant $\mathrm{N}^{\circ}$ 1662), and Istituto Toscano Tumori (ITT, DD Regione Toscana $\mathrm{N}^{\circ}$ 6888), Association for International Cancer Research (AICR, Grant $\mathrm{N}^{\circ}$ 06-0491) to AA, Ente Cassa di Risparmio di Firenze to FDC, and Veneto Regional Grant $\left(\mathrm{N}^{\circ}\right.$ 6421) to AS.

The sponsors had no involvement in study design, in the collection, analysis and interpretation of data; in the writing of the manuscript; and in the decision to submit the manuscript for publication.

\section{Conflict of interest statement}

No potential conflicts of interest were disclosed.

\section{References}

1. Siegel R, Naishadham D, Jemal A. Cancer statistics, 2013. CA Cancer J Clin 2013;63:11-30.

2. Sano T, Hollowood A. Early gastric cancer: diagnosis and less invasive treatments. Scand J Surg 2006;95:249-55.

3. Noguchi Y, Yoshikawa T, Tsuburaya A, Motohashi H, Karpeh MS, Brennan MF. Is gastric carcinoma different between Japan and the United States? Cancer 2000;89:2237-46.

4. Verdecchia A, Corazziari I, Gatta G, Lisi D, Faivre J, Forman DEUROCARE Working Group. Explaining gastric cancer survival differences among European countries. Int J Cancer 2004; 109:737-41.

5. Hanahan D, Folkman J. Patterns and emerging mechanisms of the angiogenic switch during tumorigenesis. Cell 1996;86:353-64.

6. Rak J, Yu JL, Kiement G, Kerbel RS. Oncogenes and angiogenesis: signaling three-dimensional tumor growth. J Investig Dermatol Symp Proc 2000;5:24-33.

7. Ferrara N, Gerber HP, LeCouter J. The biology of VEGF and its receptors. Nat Med 2003;9:669-76.

8. Safran M, Kaelin Jr WG. HIF hydroxylation and the mammalian oxygen-sensing pathway. J Clin Invest 2003;111:779-83.

9. Ferrara N, Kerbel R. Angiogenesis as a therapeutic target. Nature 2005;438:967-74.

10. Chen CN, Hsieh FJ, Cheng YM, et al. The significance of placenta growth factor in angiogenesis and clinical outcome of human gastric cancer. Cancer Lett 2004;213:73-82.

11. Schoenleber SJ, Kurtz DM, Talwalkar JA, Roberts LR, Gores GJ. Prognostic role of vascular endothelial growth factor in hepatocellular carcinoma: systematic review and meta-analysis. Br J Cancer 2009; 100:1385-92.

12. Smith RA, Tang J, Tudur-Smith C, Neoptolemos JP, Ghaneh P. Metaanalysis of immunohistochemical prognostic markers in resected pancreatic cancer. Br J Cancer 2011;104:1440-51.

13. Nikiteas NI, Tzanakis N, Theodoropoulos G, et al. Vascular endothelial growth factor and endoglin (CD-105) in gastric cancer. Gastric Cancer 2007:10:12-7.

14. Kolev Y, Uetake H, Iida S, Ishikawa T, Kawano T, Sugihara K. Prognostic significance of VEGF expression in correlation with COX-2, microvessel density, and clinicopathological characteristics in human gastric carcinoma. Ann Surg Oncol 2007;14:2738-47.
15. Cabuk D, Basaran G, Celikel C, et al. Vascular endothelial growth factor, hypoxia-inducible factor 1 alpha and CD34 expressions in earlystage gastric tumors: relationship with pathological factors and prognostic impact on survival. Oncology 2007;72:111-7.

16. Vidal O, Soriano-Izquierdo A, Pera M, et al. Positive VEGF immunostaining independently predicts poor prognosis in curatively resected gastric cancer patients: results of a study assessing a panel of angiogenic markers. J Gastrointest Surg 2008;12:1005-14.

17. Lieto E, Ferraraccio F, Orditura M, et al. Expression of vascular endothelial growth factor (VEGF) and epidermal growth factor receptor (EGFR) is an independent prognostic indicator of worse outcome in gastric cancer patients. Ann Surg Oncol 2008;15:69-79.

18. Lee SJ, Kim JG, Sohn SK, et al. No association of vascular endothelial growth factor-A (VEGF-A) and VEGF-C expression with survival in patients with gastric cancer. Cancer Res Treat 2009;41:218-23.

19. Yang Q, Ye ZY, Zhang JX, Tao HQ, Li SG, Zhao ZS. Expression of matrix metalloproteinase-9 mRNA and vascular endothelial growth factor protein in gastric carcinoma and its relationship to its pathological features and prognosis. Anat Rec (Hoboken) 2010;293:2012-9.

20. Chen J, Li T, Wu Y, et al. Prognostic significance of vascular endothelial growth factor expression in gastric carcinoma: a meta-analysis. J Cancer Res Clin Oncol 2011;137:1799-812.

21. Zhao ZQ, Yang S, Lu HS. Expression of midkine and vascular endothelial growth factor in gastric cancer and the association of high levels with poor prognosis and survival. Mol Med Rep 2012;5:415-9.

22. Liu L, Ma XL, Xiao ZL, Li M, Cheng SH, Wei YQ. Prognostic value of vascular endothelial growth factor expression in resected gastric cancer. Asian Pac J Cancer Prev 2012;13:3089-97.

23. Hayashi T, Yoshikawa T, Bonam K, et al. The superiority of the seventh edition of the TNM classification depends on the overall survival of the patient cohort: comparative analysis of the sixth and seventh TNM editions in patients with gastric cancer from Japan and the United Kingdom. Cancer 2013;119:1330-7.

24. Brown LF, Berse B, Jackman RW, et al. Expression of vascular permeability factor (vascular endothelial growth factor) and its receptors in adenocarcinomas of the gastrointestinal tract. Cancer Res 1993;53: 4727-33.

25. Lastraioli E, Bencini L, Bianchini E, et al. hERG1 channels and Glut-1 as independent prognostic indicators of worse outcome in stage I and II colorectal cancer: a pilot study. Transl Oncol 2012;5:105-12.

26. Galizia G, Ferraraccio F, Lieto E, et al. Prognostic value of p27, p53, and vascular endothelial growth factor in Dukes A and B colon cancer patients undergoing potentially curative surgery. Dis Colon Rectum 2004;47:1904-14.

27. Schemper M, Smith TL. A note on quantifying follow-up in studies of failure time. Control Clin Trials 1996;17:343-6.

28. Marrelli D, Pedrazzani C, Corso G, et al. Different pathological features and prognosis in gastric cancer patients coming from high-risk and low-risk areas of Italy. Ann Surg 2009;250:43-50.

29. Crociani O, Zanieri F, Pillozzi S, et al. hERG1 channels modulate integrin signaling to trigger angiogenesis and tumor progression in colorectal cancer. Sci Rep 2013;3:3308.

30. Fondevila C, Metges JP, Fuster J, et al. p53 and VEGF expression are independent predictors of tumour recurrence and survival following curative resection of gastric cancer. Br J Cancer 2004;90:206-15.

31. Ozdemir F, Akdogan R, Aydin F, et al. The effects of VEGF and VEGFR-2 on survival in patients with gastric cancer. J Exp Clin Cancer Res 2006;25:83-8.

32. Skarlos DV, Bai M, Goussia A, et al. Expression of a molecular marker panel as a prognostic tool in gastric cancer patients treated postoperatively with docetaxel and irinotecan. A study of the Hellenic Cooperative Oncology Group. Anticancer Res 2007;27:2973-83.

33. Bazas VM, Lukyanova NY, Demash DV, Galakhin KO, Myasoedov DV. Relation between cell-to-cell adhesion and angiogenesis and clinico-morphological prognostic factors in patients with gastric cancer. Exp Oncol 2008;30:235-9. 